\title{
Wheat lines exhibiting variation in tolerance of Septoria tritici blotch differentiated by grain source limitation
}

\author{
F. Collin ${ }^{\mathrm{a}}$, P. Bancal ${ }^{\mathrm{b}}$, J. Spink ${ }^{\mathrm{d}}$, P. Kock Appelgren ${ }^{\mathrm{d}}$, J. Smith ${ }^{\mathrm{e}}$, N.D. Paveley ${ }^{\mathrm{f}}$, M.O. Bancal ${ }^{\mathrm{c}}$, \\ M.J. Foulkes ${ }^{\mathrm{a}, *}$ \\ ${ }^{a}$ School of Biosciences, University of Nottingham, Sutton Bonington, Loughborough, Leicestershire LS12 5RD, UK \\ ${ }^{b}$ INRA, UMR 1402 ECOSYS, F-78850 Thiverval-Grignon, France \\ ${ }^{c}$ AgroParisTech, UMR 1402 ECOSYS, F-78850 Thiverval-Grignon, France \\ ${ }^{d}$ CELUP, Teagasc, Oak Park, Co. Carlow, Ireland \\ e ADAS UK Ltd, Sustainable Crop Management, Rosemaund, Preston Wynne, Hereford HR1 3PG, UK \\ $f$ ADAS UK Ltd, High Mowthorpe, Malton, North Yorkshire, YO17 8BP, United Kingdom
}

\begin{abstract}
Septoria tritici blotch (STB) is the most damaging disease of wheat crops in Europe. Because of the partial nature of genotypic resistance or the increasing resistance against fungicides, the tolerance, i.e. maintaining yield in the presence of expressed disease, is a relevant alternative. Tolerance is generally estimated through the yield loss per unit of source reduction, contrasts of tolerance between genotypes have been observed previously suggesting that either increasing the source availability or improving the use of stored assimilate could improve tolerance. This paper aims at developing a source/sink approach to understand the tolerance mechanism and identifying potential traits to increase tolerance of STB. A field experiment was designed to explore the relation between tolerance of STB and source/sink balance. Based on six wheat genotypes contrasting for tolerance exposed to natural STB epidemics, late nitrogen fertilization and a $50 \%$ spikelet removal were applied to change the source/sink balance. The tolerance of genotypes was quantitatively estimated over three additional field experiments. We found that STB tolerance was correlated with traits of healthy crops (high individual grain weight and high green leaf lamina area as the proportion of leaf 3 ). The spikelet removal revealed a highly variable degree of source limitation for grain filling amongst the six genotypes. Thus, we proposed an easily calculated index that highly correlated positively with the labor intensive estimation of STB tolerance. Finally, potential yield and tolerance were not correlated, which suggests that breeding for yield performance and tolerance could be possible.
\end{abstract}

Keywords: STB, tolerance, trait, source/sink, wheat

\footnotetext{
${ }^{*}$ Corresponding author

Email addresses: francois.collin@nottingham.ac.uk (F. Collin), pierre.bancal@inra.fr (P. Bancal), marie-odile.bancal@inra.fr (M.O. Bancal), john.foulkes@nottingham.ac.uk (M.J. Foulkes)
} 


\section{Highlights}

- Tolerance of STB in six wheat genotypes was correlated with traits of healthy crops.

- Low source limitation for grain filling is a genotype-specific tolerance trait.

- The grain weight in healthy crops was colimited by source and sink.

- Sink manipulation by late degraining can help screening for STB tolerance traits.

\section{Introduction}

The Septoria tritici blotch (Zymoseptoria tritici, STB) is responsible for substantial grain yield loss of wheat crops in Europe (Burke \& Dunne, 2006). Genotype resistances to the disease in wheat are partially effective, and fungicide-based strategies are marked by a sharp increase in pathogen resistance (e.g. northern France, Cheval et al. 2017, the UK, Fraaije et al. 2003). At the same time, economic, environmental and sociological contexts demand reduced use of inputs on wheat crops in Europe. Given these pressures and pathogen potential to circumvent genotype resistances or fungicide activity, disease tolerance - the maintenance of crop grain yield in the presence of expressed disease (Ney et al., 2013) - is a relevant approach to protect grain yield.

There is a genetic potential for tolerance of foliar diseases in wheat (e.g. hard wheat $\times$ leaf rust (Puccinia recondita), Kansas, USA, Salmon \& Laude 1932; spring wheat $\times$ STB, Israel, Ziv \& Eyal 1978). Formerly, Schafer (1971) considered tolerance as a relative property, evident by comparison of crops exposed to comparable severity disease (Bingham et al., 2009). Attempts to quantify tolerance have considered the effect of STB on the healthy area duration (HAD, the area under the green leaf lamina area progress curve) that summarises the variability of the canopy size across genotypes and sites and seasons (Parker et al., 2004). The STB symptoms on the upper leaves reduce the HAD, and therefore the grain yield loss per unit of HAD reduction was used as a quantitative trait of the wheat crops for STB intolerance in tolerance studies (Parker et al., 2004; Foulkes et al., 2006; Castro \& Simón, 2016). Because of poor repeatability of STB epidemics, however, the traits of healthy crops have been screened in an attempt to improve tolerance and understand underlying mechanisms (Bancal et al., 2015). Given the tolerance estimation method grain source or sink traits are potential candidate traits.

The grain yields of wheat crops in Europe are mostly sink limited or co-limited under favourable conditions (Acreche \& Slafer, 2009; Slafer \& Savin, 1994; Cartelle et al., 2006), but disease, through decreasing HAD, could modify this pattern. The source/sink balance in healthy crops might therefore be related to tolerance of foliar disease. Thus, when HAD per grain is high in healthy crops, yield loss is low when disease decreases HAD, resulting in high tolerance.

This was supported by Foulkes et al. (2006) who, studying three pairs of near isogenic lines (NILs), detected a negative correlation between STB tolerance and grains $\cdot \mathrm{m}^{-2}$ indicative of crop sink size. It was 
assumed that the UK breeding trends led to the increase in grains $\cdot \mathrm{m}^{-2}$ observed in modern cultivars in the study while maintaining equivalent potential grain size (Shearman et al., 2005); this increased grains $\cdot \mathrm{m}^{-2}$ but also decreased the sink limitation conferring higher susceptibility to yield loss when exposed to source limitation because of STB. While studying wheat yield losses due to STB in France, Bancal et al. (2015) pooled the results of three field-experiments (seven sites, at least two seasons, and 18 varieties). They identified a highly significant negative correlation amongst cultivars between HAD per grain in healthy crops and intolerance. In other words high source/sink balance increased tolerance.

Source traits have also been found to be correlated with STB tolerance in wheat. Parker et al. (2004) hypothesised that increased radiation-use efficiency (above-ground dry matter per unit of radiation interception; RUE) associated with the 1BL/1RS chromosome translocation reduced tolerance: the loss of green area and light interception may cause larger source reduction in genotypes with higher RUE. The green canopy area, light extinction coefficient and leaf photosynthetic traits were proposed to be candidate traits for tolerance of STB (Parker et al., 2004; Bingham et al., 2009). Foulkes et al. (2006) identified on wheat near-isogenic lines (NILs) that the flag-leaf area was positively correlated with tolerance of STB, which could be related to the upward movement of the pathogen through the canopy leaf layers by rain-splash events with an advantage for those genotypes with relatively more light interception in the flag leaf layer. Bancal et al. (2015) did not observe a significant effect of flag-leaf area, but they confirmed its interest through the timing of senescence: crops with later flag-leaf senescence exhibited greater tolerance.

It is possible that up-regulation of photosynthesis in remaining healthy tissues may compensate partially for source reduction caused by STB. The tolerant spring wheat cv. Miriam (Ziv \& Eyal, 1978) showed an enhanced carbon fixation by the healthy tissues (Zuckerman et al., 1997). Furthermore, Reynolds et al. grains $\cdot \mathrm{m}^{-2}$ was increased by row opening during booting, compared to a control treatment. Although not validated yet, tolerance could rely on post-anthesis RUE increase in response to lower assimilate availability relative to sink strength. More recently, Zhang et al. (2014) suggested a positive feedback from the sink strength on sources: an altered source/sink balance, decreased by ear shading or increased by spikelet rate.

Several hypothesis were tested in the present study. Firstly, a high source/sink balance is a STB tolerance trait. Secondly, wheat is mainly sink limited, so manipulations that extend source or decrease sink would increase tolerance. Finally, genotype would impact similarly source:sink balance during grain filling and STB tolerance

The link between tolerance of STB and source/sink balance is important but remains largely unclear. Our aim was to investigate further this link using six wheat genotypes contrasting for tolerance of STB that were source/sink manipulated during a field experiment. The literature reports that source/sink manipulations after grain setting (e.g. shading, defoliation, ear trimming) have been used previously by 
other authors to understand the source/sink balance effect on grain growth and direct strategies to increase the yield of wheat (Serrago et al., 2013; Slafer \& Savin, 1994; Ma et al., 1996) or barley (Cartelle et al., 2006) or soybean (Egli \& Bruening, 2001). In this study, fungicide treatment was applied to induce differences in HAD reduction and yield loss linked to STB epidemic at the crop scale. In addition, a late nitrogen fertilizer treatment was applied at booting to delay leaf senescence thus increase source during grain filling. Lastly, a spikelet removal treatment was applied at anthesis plus 13 days, removing the upper half of ear. The HAD, yield and tolerance were calculated to test the preceding hypotheses.

\section{Materials and methods}

\subsection{Genotypes screened for tolerance}

The studied genotypes were part of a large panel derived from two doubled-haploid populations which

were screened for STB tolerance and yield potential. The first population was derived from a cross between UK spring wheat Cadenza and UK winter wheat Lynx $(\mathrm{C} \times \mathrm{L})$, the second from a cross between UK winter wheat Rialto and the Mexican CIMMYT spring wheat LSP2 of large ear-phenotype (LSP2 $\times$ R). The LSP $2 \times R$ lines were included in order to obtain a wider range of source/sink phenotypes to study STB tolerance in high yielding genotypes. The full details of this preliminary STB tolerance screening in three field experiments are out of the scope of this paper for which six genotypes were selected, that are contrasted for STB tolerance.

Briefly, these three experiments were sown: i) 8 October 2013 at ADAS (Herefordshire, United Kingdom, $52.2627^{\circ} \mathrm{N} 2.8477^{\circ} \mathrm{W}$ ) following a crop of winter oats, ii) 10 October 2011 at ADAS (Herefordshire, United Kingdom, 52.1403 ${ }^{\circ} \mathrm{N} 2.8315^{\circ} \mathrm{W}$ ), and iii) 1 November 2011 at Teagasc Oak Park (Carlow, Ireland, $\left.52.8637^{\circ} \mathrm{N} 6.9136^{\circ} \mathrm{W}\right)$ following a crop of winter oilseed rape. The crops were exposed to natural STB epidemics and fungicides were used to provide STB protection to contrast with control plots. Intolerance $i_{e g}$ of each genotype $(g)$ was calculated in each experiment $(e)$ as $[\Delta Y i e l d / \Delta H A D]_{e g}$ (grain yield loss per unit of healthy area duration reduction) as described by Foulkes et al. (2006). A genotype crop tolerance grade $T$ (without unit) was then calculated as $-1 \times$ the genotype average of $i_{e g}$ standardized beforehand by environment (Eq. 1).

$$
T=\frac{-1}{n_{e}} \sum_{e=1}^{3} \frac{i_{e g}-\mu_{e}}{s d_{e}}
$$

With: $\mu_{e}, s d_{e}, n_{e}$ the environment average, standard deviation and number.

\subsection{Experimental design and treatments}

The main field experiment of our study was grown in 2014-5 on a silty clay loam soil in Herefordshire United Kingdom, $52.1403^{\circ} \mathrm{N} 2.8315^{\circ} \mathrm{W}$ ). Air temperature (1 m above ground surface) was recorded hourly by a weather station at Weobley located $3 \mathrm{~km}$ from the site. Using a split plot design, the combinations 
of 6 genotypes $(\mathrm{G})$ and 2 fungicide treatments $(\mathrm{F})$ were allocated in 3 replicates, 36 main plots in total, according to a fully randomized design. The 36 main plots $(2 \times 14 \mathrm{~m}, 14 \mathrm{~cm}$ inter-row space, 12 rows $)$ were sown on 28 October 2014, at a density of $350 \mathrm{seeds} \cdot \mathrm{m}^{-2}$ and managed according to the local best practice, with the exception of fungicide and nitrogen management. Each plot was split into two zones for the application of the late nitrogen treatment $(\mathrm{N})$. In addition, a direct sink manipulation treatment $(\mathrm{S})$ was applied within each split plot, on ear-bearing shoots of average ear length $( \pm 5 \%)$ which were identified at GS65 and tagged.

Two disease control treatments were applied (F) to obtain either a full control of STB (F1) or no control of STB (F0) while maintaining the non-targeted disease symptoms at low levels. This was based on three fungicide applications targeting growth stages (Zadoks et al., 1974) stem extension (GS32, 13 May), flag leaf emergence (GS39, 30 May) and ear emergence (GS59, 10 June). Pyraclostrobin, proquinazid, cyflufenamid were used for F0 (to control rusts and mildew) and epoxiconazole, metconazole, chlorothalonil were added for F1 to control STB. Each combination of G and F was repeated in three replicates.

The general nitrogen fertilization of the experimental area consisted of $220 \mathrm{~kg} \mathrm{~N} \cdot \mathrm{ha}^{-1}$, split into 3 applications before GS51 on 21 March, 18 April and 9 May). In order to study the effect of nitrogen content at anthesis for a given canopy structure and grain number per ear, a late Nitrogen treatment (N) was applied at GS51 and consisted of an additional nitrogen fertilization input $\left(\mathrm{N} 1,+40 \mathrm{~kg} \cdot \mathrm{ha}^{-1}\right) \mathrm{versus}$ a control $\left(\mathrm{N} 0,+0 \mathrm{~kg} \cdot \mathrm{ha}^{-1}\right)$. The $\mathrm{N} 1$ treatment was applied on a $3 \mathrm{~m}$ plot length at the end of each plot. Using a backpack sprayer equipped with a single $1 \mathrm{~m}$ length lance with a regular nozzle, $54 \mathrm{~g}$ of ammonium nitrate (34.4\% of Nitrogen content) was applied under the canopy. An adjacent zone of $3 \mathrm{~m}$ length zone was dedicated to the control N0.

Genotype anthesis date (GS65) was precisely estimated for each genotype. Spikelet removal manipulation (S) was applied on average 13 days after anthesis (daa), which corresponded to a range of $163-271^{\circ} \mathrm{Cd}$ after anthesis (degree-days, base temperature $0^{\circ} \mathrm{C}$ ). This timing prevented any effect on endosperm cell division potential grain weight and grain sink size (Dupont \& Altenbach, 2003), while increasing assimilate availability per grain. Within each $\mathrm{N}$ treatment, the top-half of 10 randomly selected ears was removed (S1, the spikelets count divided by two, rounded up if odd number) while 20 other ears remained intact as a control (S0). This method reduced the wound stress and transpiration stream perturbations in the ear in comparison to spikelet removal from one side of the ear. No interaction has been found between genotype and the horizontal or vertical spikelet removal methods in spring wheat (Reynolds et al., 2012). The upper part of the ear was collected, oven dried and weighed. At this stage, three replicates of $6 \mathrm{G} \times 2 \mathrm{~F} \times 2 \mathrm{~N} \times$ $2 \mathrm{~S}=48$ treatment combinations were identified.

\subsection{Crop measurements}

Shortly before GS65, the length of 75 ears in total per genotype was measured randomly across all the plots in the experiment. Then 60 ear bearing shoots representative of the average $( \pm 5 \%)$ of the genotype population were identified per plot and tagged. Five tagged shoots were cut at ground level in each nitrogen 
treatment within each plot at mid-anthesis (GS65, A) and at A+13 daa (day after anthesis, i.e. the day of spikelet removal treatment). Similarly, five-shoot samples were collected in each nitrogen $\times$ spikelet removal treatment combination at $\mathrm{A}+26$ daa $\left(387-483^{\circ} \mathrm{Cd}\right.$ after anthesis) and at maturity (i.e. after kinetics were fitted to Eq. 2 (Bancal et al., 2015) for each leaf layer and for the cumulated three upper leaves (uppermost leaf being the flag leaf). For the whole dataset, $\mathrm{R}^{2}$ was 0.98 , and root mean square error of estimations was $5 \%$ GLA.

$$
\% G L A(t, K, D, I)=K \cdot \exp \left(-\exp \left(\frac{2 \times(I-t)}{D}\right)\right)
$$

With: \%GLA, percentage of green leaf lamina area; $t$, thermal time since heading stage (unit dd $\mathrm{H}_{\mathrm{H}}$ : degree-

The five-shoot samples were dissected. The lamina of leaf 1 (flag leaf), leaf 2 and leaf 3 was detached at the ligule. Green, diseased and senescent leaf lamina areas were visually scored for each leaf layer as a percentage of total leaf lamina area. Ears were cut at the ear collar and the stem and leaf sheath was separated into the upper internodes (peduncle, internode 2, internode 3 ) by cutting above the nodes and the green and senescent and diseased percentage areas were scored in situ using the same methodology on a weekly basis in the weeks when no sampling was scheduled, totalling eight leaf lamina assessments from mid-anthesis to physiological maturity.

The width and length of the top three leaf layers were measured in each plot on four randomly selected ear-bearing shoots at two stages (GS59 and GS59 + 20 days in each plot). Leaf lamina area per ear-bearing shoot (LAe) was estimated per leaf layer: width $\times$ length $\times 0.83$ (Bryson et al., 1997).

The number of fertile ears was counted at GS75 in four randomly selected $0.5 \mathrm{~m}$ row lengths per plot, to estimate the density of ear-bearing shoots (ENm, unit: shoots $\left.\cdot \mathrm{m}^{-2}\right)$. Grain number per ear (GNe) and thousand grain weight (TGW) were measured on the five-shoot samples at $\mathrm{A}+13$ daa and at $\mathrm{A}+26$ daa and at maturity. The two last assessments were averaged to provide GNe estimation. The yield per ear (Ye) was calculated from GNe and TGW. The ear density assessed at plot scale (ENm) was used to estimate the grains $\cdot \mathrm{m}^{-2}(\mathrm{GNm})$ and the grain yield $\cdot \mathrm{m}^{-2}$ at $\mathrm{A}+13$ daa, at $\mathrm{A}+26$ daa and at maturity $\left(\mathrm{Ym}, Y m=E N m \cdot G N e \cdot T G W \cdot 1000^{-1}\right)$.

\subsection{Data analysis}

In every replicate of $\mathrm{G} \times \mathrm{F} \times \mathrm{N} \times \mathrm{D}$ combination, percentage of Green Leaf Lamina Area (\%GLA) days since heading stage, base temp. $0^{\circ} \mathrm{C}$ ); $K$, left asymptote set to $100 \%$; $D$, the duration of rapid senescence (approximately between $80 \%$ and $20 \%$ GLA; unit ${ }^{\circ} \mathrm{Cd}$ : degree-days base temp. $0{ }^{\circ} \mathrm{C}$ ); $I$, inflexion point of the kinetic which occurs when $37 \%$ of the lamina area is green, indicating the time of the senescence (unit $\mathrm{dd}_{\mathrm{H}}$ ).

The area under the \%GLA fitted curve was calculated and then scaled to the individual shoot using the leaf lamina areas to obtain the Healthy Area Duration per ear-bearing shoot $\left(\mathrm{HADe}, \mathrm{unit}^{2} \cdot \mathrm{dd}_{\mathrm{H}} \cdot \mathrm{shoot}^{-1}\right)$. 
Also, the HADe was converted to the single grain scale $\left(\mathrm{HADg}\right.$, unit: $\left.\mathrm{dm}^{2} \cdot \mathrm{dd}_{\mathrm{H}} \cdot \mathrm{grain}^{-1}\right)$ or the crop scale (HADm, unit: $\left.\mathrm{m}^{2} \cdot \mathrm{dd}_{\mathrm{H}} \cdot \mathrm{m}^{-2}\right)$.

Dry matter fluxes $(\triangle D M)$ were estimated during the grain filling period. They were scaled to a standard grain number estimation ( $\mathrm{sGNe}$ ) which was the average GNe observed per $\mathrm{G} \times \mathrm{F} \times \mathrm{N} \times \mathrm{S}$ combination, multiplying the observed dry matter biomass - associated with an observed GNe - by the ratio $s G N e / G N e$. Dry matter flux analyses were applied for above-ground biomass, vegetative parts and grains.

The percentage increase assimilate availability per grain in the spikelet removal treatment was calculated, either based on GNe reduction (Eq. 3, Slafer \& Savin 1994; Borrás et al. 2004) or on HADg increase (Eq. 4).

$$
\begin{aligned}
& 100 \times\left(\frac{G N e_{S 0}}{G N e_{S 1}}-1\right) \\
& 100 \times\left(\frac{H A D g_{S 1}}{H A D g_{S 0}}-1\right)
\end{aligned}
$$

The experiment was a factorial experiment with three spatial scales (P main plot, N split-plot, S spikelet removal) and thus three different error variances. The analysis of responses (e.g. yield components) to treatments was based on split-plot ANOVAs, based on mixed models (Crawley 2012, Eq. 5).

$$
y_{i j k l m}=\mu+f_{i}+g_{j}+P_{i j k}+N_{l(i j k)}+S_{m(l i j k)}+\varepsilon_{i j k l m}
$$

With: $y_{i j k l m}$, an observed value of a response variable; $\mu$, the population mean for the reference; $f_{i}$, the fungicide fixed effect; $g_{j}$, the genotype fixed effect; $P_{i j k}$, the main plot random effect ( $k$ plots for each $[F \times G]_{i j}$ combination); $N_{l(i j k)}$, the nitrogen fixed effect nested within a plot (sub-plot); $S_{m(l i j k)}$, the spikelet removal fixed effect nested within the nitrogen split-plot.

Fixed effects were tested with the Wald chi-square including up to 3-way interactions between fixed effects, removing non-significant effects. Effect size was then calculated and least square means were plotted along with the $95 \%$ confidence interval (CI) when relevant. Eventually, post-hoc tests were performed to obtain least means square comparison between levels of factors, relying on Tukey's Honest Significant Difference test (Tukey HSD).

Statistical analysis was carried out using R (R Core Team, 2017). Supplementary packages included: DBI (R Special Interest Group on Databases, 2014) and RPostgreSQL (Conway et al., 2016) for data management and variable calculations, nlme (Pinheiro et al., 2017) for mixed models fitting, Ismeans (Lenth, 2016) for Tukey HSD based post-hoc tests, package lattice (Sarkar, 2008) for graphics.

\section{Results}

\subsection{The tolerance grade of the genotypes}

The three preliminary experiments were exposed to severe natural STB epidemics, as the maximum yield loss in comparison to the control reached $-69 \%$ (Table 1 ). The intolerance $\left(i_{e g}\right)$ for the six genotypes 

expected to be tolerant, and $\mathrm{LSP} 2 \times \mathrm{R} 16, \mathrm{C} \times \mathrm{L} 7 \mathrm{~A}, \mathrm{C} \times \mathrm{L} 5 \mathrm{H}$ to be intolerant in the main experiment at ADAS Hereford 2015, which explored the relation between STB tolerance and source/sink balance.

Table 1: Estimation of the genotype tolerance. Intolerance $\left(i_{e g}\right.$ of the six doubled-haploid genotypes $(g)$ was calculated in the three field experiments (e; 2011-2012 and 2013-2014 at ADAS, Hereford, and 2011-2012 at Teagasc, Carlow, Ireland; respectively ADAS 2012, ADAS2014, Teagasc 2012) as $[\Delta \text { grain yield } / \Delta H A D]_{e g}$ (unit:kg $\cdot \mathrm{d}^{-1} \cdot \mathrm{ha}^{-1}, 85 \%$ DM per HAD in days since GS59). The genotype tolerance grade (T) was calculated as $-1 \times$ the genotype average of $i_{e g}$, beforehand standardized by environment (without unit). The last line is the maximum grain yield loss as a percentage of the STBprevented crops.

\begin{tabular}{lccccccr} 
& \multicolumn{3}{c}{ HAD Reduction $(\%$ Treated $)$} & \multicolumn{3}{c}{ Intolerance $\left(i_{e g}, \mathrm{~kg} \cdot \mathrm{d}^{-1} \cdot \mathrm{ha}^{-1}\right)$} \\
Genotype & ADAS 2012 & ADAS 2014 & Teag. 2012 & ADAS 2012 & ADAS 2014 & Teag. 2012 & T \\
\hline C $\times$ L 14B & -29 & -23 & -37 & 57 & 21 & 7 & 0.23 \\
C $\times$ L 5H & -40 & -35 & -53 & 11 & 32 & 31 & -0.02 \\
C $\times$ L 7A & -60 & -49 & -56 & 73 & 49 & 43 & -1.45 \\
LSP2 $\times$ R 127 & -14 & -17 & -41 & 22 & 18 & 2 & 0.81 \\
LSP2 $\times$ R 16 & -33 & -38 & -67 & 68 & 28 & 27 & -0.48 \\
LSP2 $\times$ R 20 & -30 & -34 & -51 & 11 & 19 & 2 & 0.91 \\
\hline max. yield loss & $-69 \%$ & $-42 \%$ & $-40 \%$ & & & &
\end{tabular}

\subsection{Variability of grain filling source traits}

In the experiment at ADAS Hereford 2015, leaf area per ear-bearing shoot (LAe) varied by $10 \%$ between the lowest LSP $2 \times \mathrm{R} 127$ and the highest LSP $2 \times \mathrm{R} 16$ genotypes $(\mathrm{P}<0.001$; Table 2$)$. In intact ears $(\mathrm{S} 0)$ the LAe and GNe were positively correlated $\left(\mathrm{r}=0.37^{* *}\right)$; therefore in comparison to the LAe, the range of Leaf Area per grain ( $\mathrm{LAg}$ ) was reduced varying only by $6 \%$. The spikelet removal (S1) not only increased LAg, but also increased the variability between genotypes and modified the ranking of the genotypes for LAg. Neither fungicide nor $\mathrm{N}$ fertilization affected LAg. In plots where no fungicide STB control was applied (F0), the timing of canopy senescence (I) varied according to genotype $(\mathrm{P}<0.001)$; it was significantly, although marginally, delayed following both $\mathrm{N}$ fertilization and spikelet removal treatments by about $20^{\circ} \mathrm{Cd}$, that is, approximatively one day $(\mathrm{P}<0.05)$. The STB disease severity was generally low with maximum values (expressed as proportion of leaf area with symptoms cumulated for the upper three leaves) ranging from 0.04-0.11 amongst the six lines in F0 plots (Fig. 1). There was also a small amount of yellow rust (YR) observed in some lines with maximum YR severity ranging from 0.00-0.05 amongst the six lines in F0 plots, affecting mainly LSP2 $\times$ R 127 (Fig. 1). Therefore, the disease severity was confounded with senescence progression during the mid grain filling stage, explaining the apparent decrease in severity; 


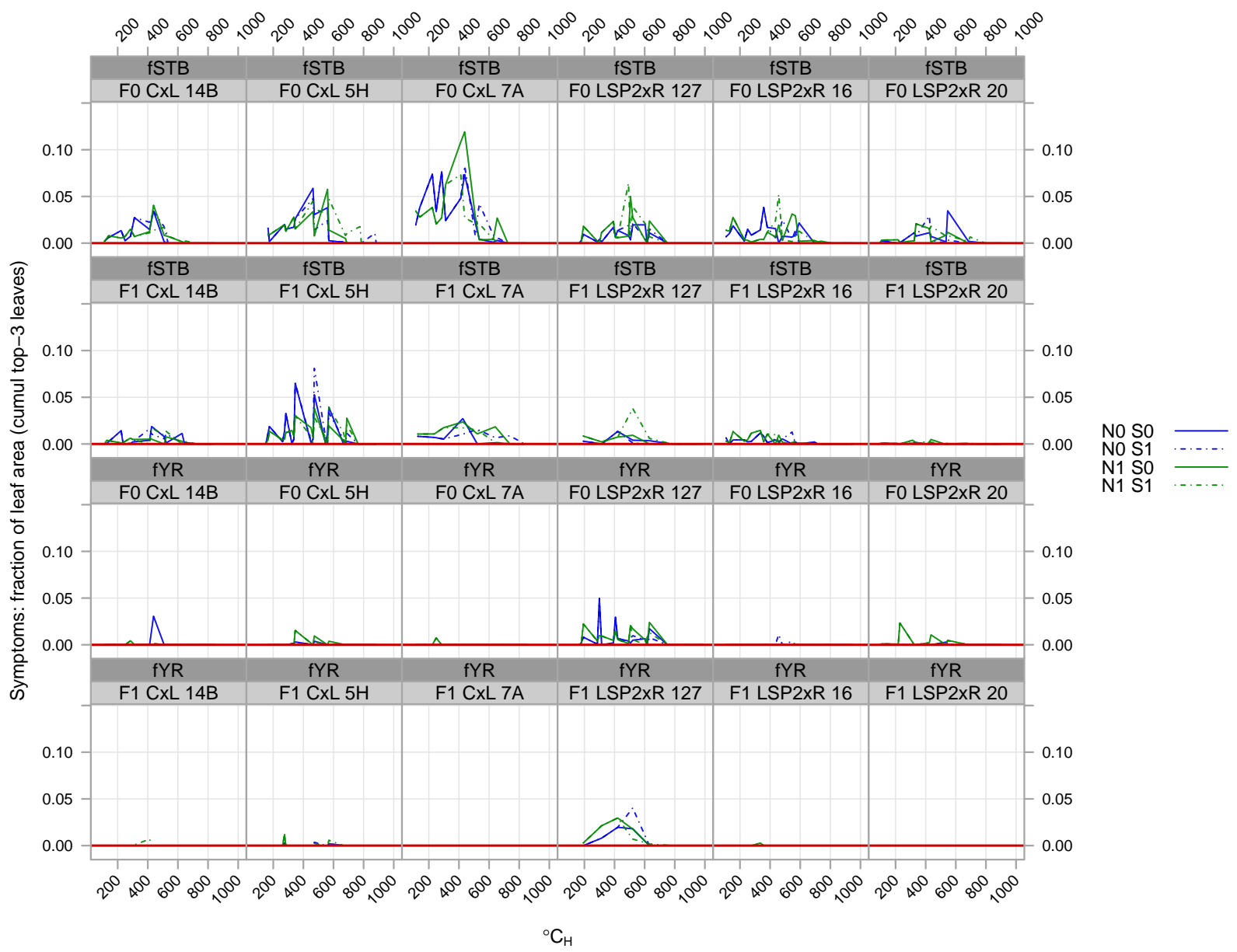

Figure 1: Disease severity (fraction of leaf area with symptoms) at each date for each combination of Genotype, Fungicide, Nitrogen and Spikelet removal treatment. Values are average symptoms assessment (cumulated for the three upper leaves). The $\mathrm{x}$-axis is thermal time since heading stage (GS55). The two upper rows of panels correspond to the STB disease assessment (fSTB), the two bottom rows are the yellow rust assessment (fYR). The F1 treatment is the full fungicide treatment, F0 no control of STB. The lines and colours correspond to the Nitrogen $\times$ Spikelet removal treatment. 
Table 2: Analysis of variance of different grain source traits in the field experiment at Herefordshire 2014-15. Response of leaf area per ear-bearing shoot (LAe), fraction of leaf 3 on total leaf area (fLA3), leaf area per grain in (LAg), canopy senescence time (I, unit $\mathrm{dd}_{\mathrm{H}}$ : degree-days since heading stage, base temp. $0^{\circ} \mathrm{C}$ ) and duration $(\mathrm{D})$, stem DM per grain variation during late grain filling (after spikelet removal, $\triangle \mathrm{DMst}$ ) to the genotype, the fungicide treatment, the nitrogen treatment, the spikelet removal treatment. The symbol $\$$ indicates that results were obtained by paired comparison because of deviation from ANOVA hypotheses. The symbol $\S$ indicates LSP $2 \times \mathrm{R} 16$ was removed from the ANOVA. When not significant or non-applicable, 'ns' and 'na' are reported. All interactions were tested but non-significant.

\begin{tabular}{|c|c|c|c|c|c|c|c|c|c|}
\hline & $\begin{array}{l}\text { LAe } \\
\mathrm{cm}^{2} / \mathrm{e}\end{array}$ & fLA3 & $\begin{array}{l}\mathrm{LAg}(\mathrm{S} 0) \\
\mathrm{cm}^{2} / \mathrm{gr}\end{array}$ & $\begin{array}{l}\mathrm{LAg}(\mathrm{S} 1) \\
\mathrm{cm}^{2} / \mathrm{gr}\end{array}$ & $\begin{array}{l}\mathrm{I}(\mathrm{F} 0) \\
\mathrm{dd}_{\mathrm{H}}\end{array}$ & $\begin{array}{l}\mathrm{I}(\mathrm{F} 1) \\
\mathrm{dd}_{\mathrm{H}}\end{array}$ & $\begin{array}{l}\mathrm{D} \S \\
{ }^{\circ} \mathrm{Cd}\end{array}$ & $\begin{array}{l}\Delta \mathrm{DMst}(\mathrm{S} 0) \\
\mathrm{mg} / \mathrm{e}\end{array}$ & $\begin{array}{l}\Delta \mathrm{DMst}(\mathrm{S} 1) \\
\mathrm{mg} / \mathrm{e}\end{array}$ \\
\hline Genotype & $* * *$ & $* * *$ & $* *$ & $* * *$ & $* * *$ & $* * *$ & $* * *$ & $* * *$ & $\mathrm{~ns}$ \\
\hline $\mathrm{C} \times \mathrm{L} 14 \mathrm{~B}$ & $70.9 \mathrm{~b}$ & $0.289 \mathrm{~b}$ & $1.32 \mathrm{ab}$ & $2.67 \mathrm{~d}$ & $594 a$ & $649 \mathrm{bc}$ & $205 \mathrm{~b}$ & $13.6 \mathrm{~b}$ & 25.9 \\
\hline $\mathrm{C} \times \mathrm{L} 5 \mathrm{H}$ & $66.2 \mathrm{ab}$ & $0.292 \mathrm{~b}$ & $1.22 \mathrm{ab}$ & $2.41 \mathrm{bcd}$ & $645 \mathrm{bc}$ & $676 \mathrm{c}$ & $264 \mathrm{c}$ & $9.4 \mathrm{a}$ & 18.8 \\
\hline $\mathrm{C} \times \mathrm{L} 7 \mathrm{~A}$ & $68.7 \mathrm{~b}$ & $0.275 \mathrm{a}$ & $1.18 \mathrm{a}$ & $2.25 \mathrm{~b}$ & $609 a$ & $685 \mathrm{c}$ & $248 \mathrm{c}$ & $12.0 \mathrm{ab}$ & 21.5 \\
\hline $\mathrm{LSP} 2 \times \mathrm{R} 127$ & $63.1 \mathrm{a}$ & $0.321 \mathrm{c}$ & $1.24 \mathrm{ab}$ & $2.01 \mathrm{a}$ & $610 \mathrm{a}$ & $557 \mathrm{a}$ & $163 a$ & $17.4 \mathrm{c}$ & 24.7 \\
\hline $\mathrm{LSP} 2 \times \mathrm{R} 16$ & $84.5 \mathrm{c}$ & $0.274 \mathrm{a}$ & $1.29 \mathrm{ab}$ & $2.55 \mathrm{~cd}$ & $616 a b$ & $635 \mathrm{~b}$ & $329 \mathrm{~d} \S$ & $13.6 \mathrm{~b}$ & 21.4 \\
\hline $\mathrm{LSP} 2 \times \mathrm{R} 20$ & $70.9 \mathrm{~b}$ & $0.327 \mathrm{c}$ & $1.37 \mathrm{~b}$ & $2.37 \mathrm{~cd}$ & $659 \mathrm{c}$ & $629 \mathrm{~b}$ & $167 \mathrm{a}$ & $13.7 \mathrm{~b}$ & 23.5 \\
\hline Fungicide & ns & ns & ns & ns & \multicolumn{2}{|c|}{$* * \$$} & $* * * \S$ & $\mathrm{ns}$ & ns \\
\hline F0 & 71.1 & 0.297 & 1.27 & 2.43 & \multicolumn{2}{|l|}{622} & $225 \mathrm{a}$ & 13.8 & 22.1 \\
\hline $\mathrm{F} 1$ & 70.4 & 0.296 & 1.27 & 2.33 & & 639 & $194 \mathrm{~b}$ & 12.8 & 23.1 \\
\hline Fertilization & & & ns & ns & $* *$ & ns & $\mathrm{ns} \S$ & ns & ns \\
\hline No & na & na & 1.28 & 2.41 & $614 a$ & 637 & 208 & 13.4 & 22.8 \\
\hline $\mathrm{N} 1$ & na & na & 1.26 & 2.35 & $633 \mathrm{~b}$ & 640 & 211 & 13.2 & 22.5 \\
\hline Spklt remov. & & & \multicolumn{2}{|c|}{$* * * \$$} & $* *$ & ns & $\mathrm{ns} \S$ & \multicolumn{2}{|c|}{$* * * \$$} \\
\hline So & na & na & 1.27 & & $596 \mathrm{a}$ & 620 & 209 & 13.3 & \\
\hline S1 & na & na & & 2.38 & $614 \mathrm{~b}$ & 623 & 210 & & 22.6 \\
\hline
\end{tabular}

consistently, senescence was hardly affected in plots where full fungicide STB control was applied (F1). It is noteworthy that LSP $2 \times \mathrm{R} 127$ exhibited earlier senescence in F1 than in F0. Finally, the fungicide effect was not significant on flag-leaf senescence; but it was highly significant on leaf 3 senescence time. So the resulting effect on canopy senescence occurred through the proportional contribution of leaf 3 to canopy lamina area (fLA3) which also varied according to the genotype $(\mathrm{P}<0.001)$, and was especially high in LSP $2 \times$ R 127 and LSP $2 \times$ R 20. Overall, a delay of the canopy senescence time (I) following fungicide application was observed, although with low significance $(\mathrm{P}<0.05)$. Unlike the senescence time, the leaf senescence duration (D) did not significantly vary with either the $\mathrm{N}$ fertilization or spikelet removal treatments. Conversely, fungicide treatment led to shorter senescence duration and large variations in duration were observed between genotypes so that LSP $2 \times \mathrm{R} 16$ had to be removed from the analysis to allow ANOVA for this trait. In addition to canopy traits, the stem dry mass after A+13 daa (the time of spikelet removal) was regarded as a secondary source of grain nutrition by carbohydrate remobilization. In Table 2 data are expressed as carbohydrate remobilization per grain. In shoots with unmanipulated ears (S0), the genotype effect was highly significant on carbohydrate remobilization per grain $(\mathrm{P}<0.001)$, while no significant effect of fungicide or fertilization was observed. Spikelet removal (S1) largely increased carbohydrate remobilization per grain, yet the genotype effect was no longer significant, neither was it for 
fungicide or fertilization.

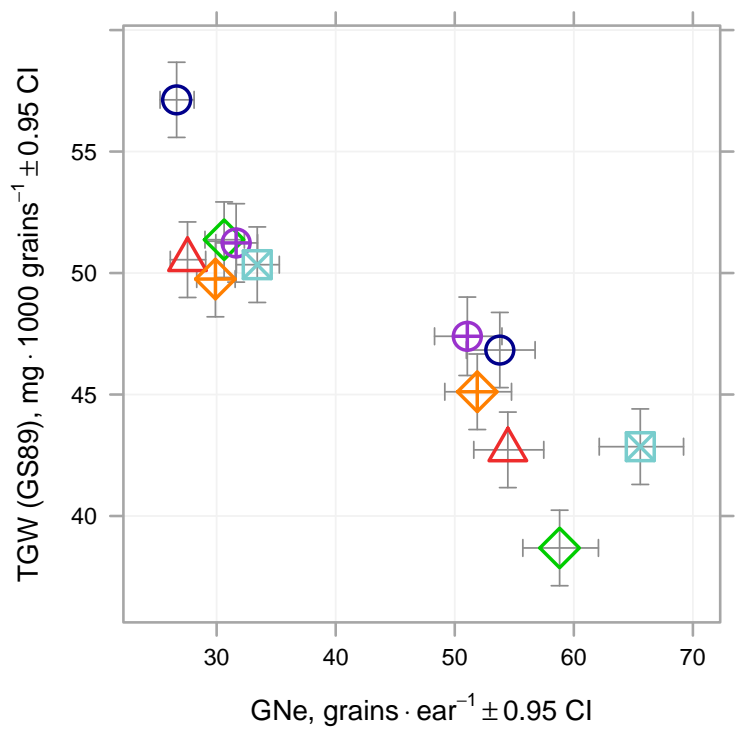

(a) TGW versus grain number per ear

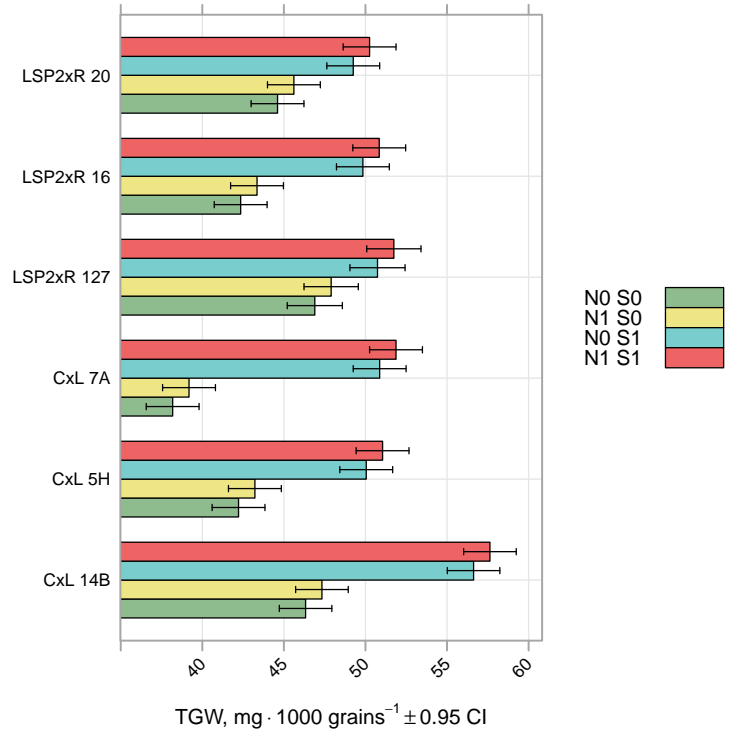

(b) TGW of each genotype

Figure 2: a) Relationship of the TGW at maturity (GS89) to the grain number per ear, according to the genotype (C $\times$ L $14 \mathrm{~B}$, dark blue empty circles; $\mathrm{C} \times \mathrm{L} 5 \mathrm{H}$, red triangles; $\mathrm{C} \times \mathrm{L} 7 \mathrm{~A}$, green empty diamonds; LSP2 $\times \mathrm{R} 127$, purple crossed circles; LSP $2 \times \mathrm{R} 16$, light blue squares; LSP $2 \times \mathrm{R} 20$, orange crossed diamonds) and to the spikelet removal treatment. b) TGW measured at maturity for the genotypes (x-axis, ordered according to their maximum TGW estimation), the nitrogen (N) and spikelet $(\mathrm{S})$ removal treatments. The values are the least mean square estimations from the ANOVA models along with the 95\% confidence interval. Effects and significance: TGW at maturity, G and $\mathrm{S}$ and $\mathrm{G} \times \mathrm{S}, \mathrm{P}<0.001$ and $\mathrm{N} \mathrm{P}=0.024 ; \mathrm{GNe}$, $\mathrm{G}$ and $\mathrm{S}$ and $\mathrm{G} \times \mathrm{S}, \mathrm{P}<0.001$ (tested on log-transformed values for homoscedasticity).

As shown in Fig. 2a grain number per intact ear $(\mathrm{S} 0)$ varied among genotypes $(\mathrm{P}<0.01)$ from 50 to 66 (LSP2 $\times$ R 16), without significant effect of fungicide or N fertilization. Removing half the spikelets reduced grain number by $40 \%$ in LSP $2 \times \mathrm{R} 127$ and LSP $2 \times \mathrm{R} 20$ versus $50 \%$ in other genotypes $(\mathrm{P}<0.001)$. No compensation in grain number per ear occurred following spikelet removal, as the grain counts on the day of treatment $(\mathrm{A}+13$ daa $)$ were consistent with those obtained later. Mean grain weight (TGW) varied at maturity (GS89) in intact ears according to genotype $(\mathrm{P}<0.001)$ and fertilization $(\mathrm{P}<0.05$, Fig. 2b). The post-heading N application (N1) significantly increased TGW (+0.9 g) without interaction with genotype. However, the fungicide treatment did not modify TGW. Removing spikelets led to a grain yield loss per ear ranging from $32 \%$ to $40 \%$; thus, the grain number reduction was not compensated by a corresponding TGW increase. The increase in final TGW of S1-ears compared to S0-ears ranged from $+9 \%$ (LSP2×R 127) to $+33 \%(\mathrm{C} \times \mathrm{L} 7 \mathrm{~A}, \mathrm{P}<0.001)$. Among S1-ears, only $\mathrm{C} \times \mathrm{L} 14 \mathrm{~B}$ had significantly heavier grains compared to the other genotypes. Overall, there was a negative correlation between the TGW response to spikelet removal and the TGW in the control $\mathrm{S} 0(\mathrm{r}=-0.74, \mathrm{P}<0.001)$. TGW was also measured at $\mathrm{A}+13$ daa, the 
time of spikelet removal. LSP $2 \times \mathrm{R} 127$ had then a higher TGW $(16.9 \mathrm{~g})$ than the other genotypes which

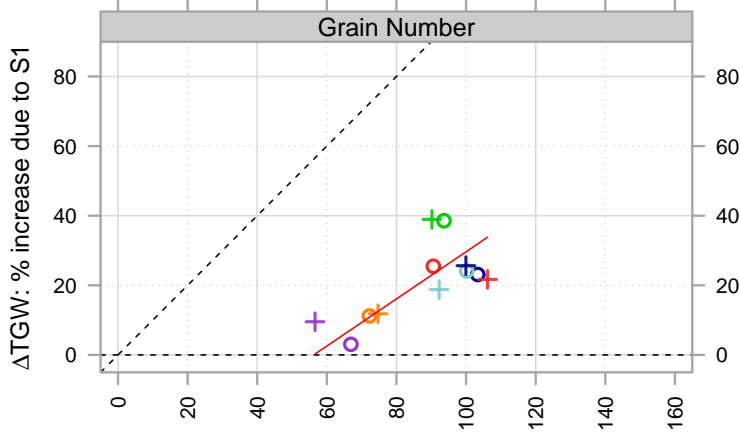

Relative increase in assimilate availability per grain (\%)

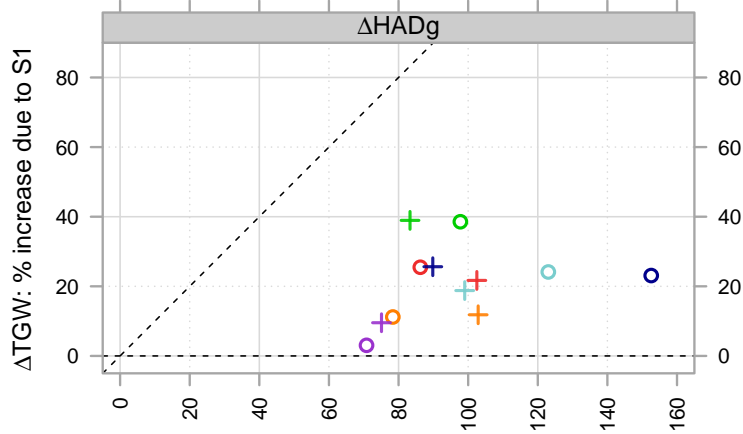

Relative increase in assimilate availability per grain (\%) (a) Grain Number per ear

Figure 3: Relationship between relative increase in grain dry weight and relative increase in assimilate availability from the time of spikelet removal $(A+13$ daa) to maturity. Relative assimilate availability increase was calculated according to methods: left, the grain number reduction per ear; right, the $\triangle \mathrm{HADg}$ increase (HAD per grain estimated since the time of spikelet removal). The dashed lines represents full source or sink limitation (slopes 1 and 0 ). The colours represents the genotypes $(\mathrm{C} \times \mathrm{L} 14 \mathrm{~B}$, dark blue; $\mathrm{C} \times \mathrm{L} 5 \mathrm{H}$, red; $\mathrm{C} \times \mathrm{L} 7 \mathrm{~A}$, green; LSP2 $\times \mathrm{R} 127$, purple; LSP2 $\times \mathrm{R} 16$, light blue; LSP2 $\times \mathrm{R} 20$, orange) and nitrogen treatment (control, circles; additional nitrogen at heading stage, crosses). The red line is the reduced major axis regression line (Smith, 2009), preferred in this case to least mean square estimation which underestimates variations along with $\mathrm{x}$-axis values; equation is $y=0.677( \pm 0.22) x-38( \pm 45)(\mathrm{P}<0.001)$.

The source/sink balance mostly varied with both genotype and spikelet removal, $\mathrm{N}$ fertilization or fungicide treatments showing a lesser effect. We thus examined if the observed variation could be interpreted by a single rule. In the literature, the relative increase in assimilate availability following spikelet removal is commonly assessed by the reduction in grain number, such as shown in Fig. 3a. A grain number reduction of $50 \%$ then leads to an increase in assimilate availability of $100 \%$, and so on according to Eq. 3 . In the present study, spikelet reduction thus created a potential increase of assimilate availability ranging from $+61 \%$ to $+106 \%$ depending on genotype and $\mathrm{N}$ fertilization. It resulted in an increase in TGW, through enhanced late grain filling (that is after $\mathrm{A}+13$ daa), ranging from 3 to $39 \%$ depending on the genotype, that was significantly correlated with the increase in assimilate availability. Regardless of genotype and treatments, $\triangle$ TGW was therefore determined by assimilate availability, although with a slope less than 1. Furthermore, the different genotypes did not exactly follow the common regression; spikelet removal in 
$\mathrm{C} \times \mathrm{L} 7 \mathrm{~A}$ apparently generated a larger $\triangle \mathrm{TGW}$ than in other genotypes (Fig. 3a). In addition, as indicated by Table 2, not only sinks, but also sources were affected by the removal of spikelets. Therefore, Fig. $3 \mathrm{~b}$ represents the relative increase in assimilate availability based on HAD per grain during the late grain filling ( $\triangle \mathrm{HADg}$ ) according to Eq. 4. Following spikelet removal, $\triangle \mathrm{HADg}$ increased from $70 \%$ to $152 \%$, yet without significant correlation with the relative increase in $\Delta \mathrm{TGW}$. We suspected it was linked to error accumulation by using relative ratios. Therefore, $\triangle \mathrm{TGW}$ was then directly correlated with $\Delta \mathrm{HADg}$ (Fig. 4), calculated from the time of spikelet removal. Fig. 4 shows a linear regression of late HADg on $\Delta$ TGW that is highly significant $(y=0.025( \pm 0.003) x+26( \pm 1.0) ; \mathrm{P}<0.001)$. The relationship of grain yield loss to HAD that is commonly used at the $\mathrm{m}^{2}$ scale can also be used at the grain scale. A crop tolerance index $(\mathrm{T})$ was previously derived from the slope of grain yield to HAD at the $\mathrm{m}^{2}$ scale between control and stressed crops in the three preliminary experiments (Table 1), and using the same rationale tolerance indices at the grain scale $(\mathrm{Tg})$ were built in the present source/sink experiment. As tolerance applies to any stress, indices could be built regarding each of the applied treatments (fungicide, fertilization and spikelet removal). However, because spikelet removal showed the largest effects, attention is focused on it hereafter. Therefore, Tg was defined as the grain weight variation per unit of HADg variation because of (and since the time of) the spikelet removal treatment: $\triangle T G W / \Delta H A D g$.

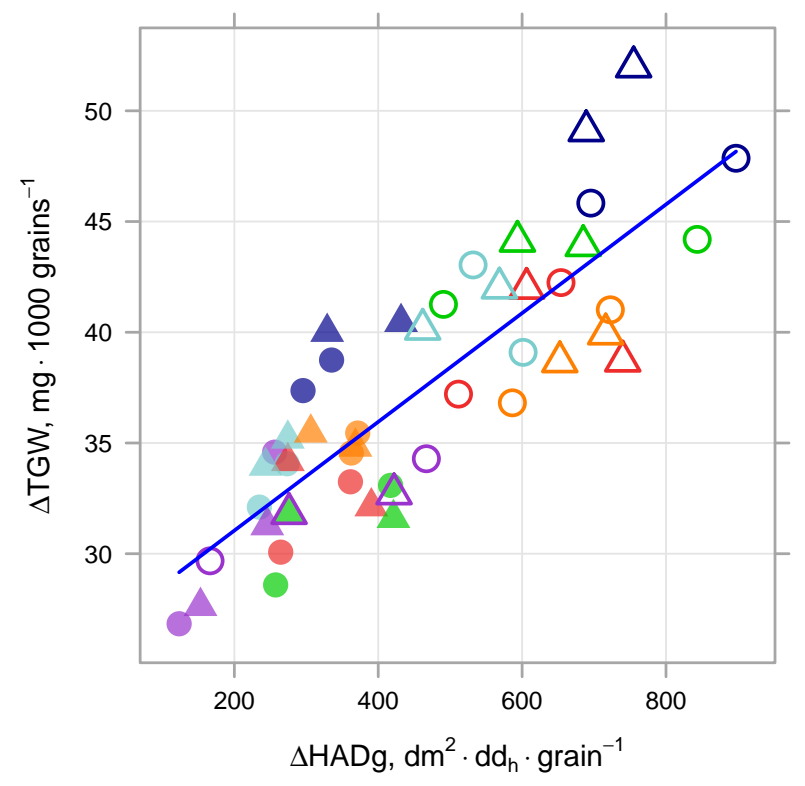

Figure 4: From the time of spikelet removal, relationship of TGW growth $(\triangle T G W)$ to HADg $(\triangle H A D g)$. Each point is the average for each genotype (colours: $\mathrm{C} \times \mathrm{L} 14 \mathrm{~B}$, dark blue; $\mathrm{C} \times \mathrm{L} 5 \mathrm{H}$, red; $\mathrm{C} \times \mathrm{L} 7 \mathrm{~A}$, green; LSP2 $\times \mathrm{R} 127$, purple; LSP2 $\times \mathrm{R} 16$, light blue; LSP $2 \times$ R 20, orange) and nitrogen treatment (control, circles; additional nitrogen at heading stage, triangles) and spikelet removal (control, full; spikelets removed, empty). The blue line is the least square mean regression fit on the cloud $\left(y=0.025( \pm 0.002) \cdot x+26( \pm 1.1), \mathrm{R}^{2}=0.71\right)$. 


\subsection{Tolerance prediction using source and sink traits}

From our results, we tried to obtain a prediction of STB tolerance at the $\mathrm{m}^{2}$ scale using the various

source and sink traits measured. Unfortunately, the low STB pressure combined with minor yellow rust symptoms prevented estimating STB tolerance from our assay. However, the six genotypes had been previously characterized for their STB tolerance in three independent field experiments as described above (Table 1). Hypothesizing tolerance was at least partly genetically determined, a single tolerance grade $\mathrm{T}$ was then calculated according to Eq. 1 yielding a value that extended from $1.45 \pm 0.35(\mathrm{C} \times \mathrm{L} 7 \mathrm{~A}$, intolerant) to $0.91 \pm 0.14$ (LSP $2 \times \mathrm{R} 20$, tolerant). $\mathrm{T}$ was further correlated with various traits observed during the present experiment (Table 3). Some of these traits were recorded using only the control treatment (S0), while others combined observations on S0 and S1 plants. In each case the reported values pooled all the data from $\mathrm{F} 0 / \mathrm{F} 1$ and N0/N1 treatments.

Among the traits observed on S0 crops, TGW was correlated with T $(\mathrm{P}<0.05)$, as well as several traits related to leaf 3 . On the other hand, traits linked to the flag leaf or the whole canopy did not correlate with $\mathrm{T}$, neither did stem DM mobilization nor late grain filling $\Delta \mathrm{TGW}$. However, the difference in late grain filling $\Delta$ TGW between S1 and S0 was negatively correlated with T. No other combined S1 and S0 traits were significantly correlated with $\mathrm{T}$, even those traits related to canopy or leaf 3 . Interestingly $\mathrm{Tg}$ correlated very tightly with $\mathrm{T}(\mathrm{P}<0.001)$.

\section{Discussion}

The experiment provided large source/sink balance variations that could be related to the tolerance T of the six genotypes, assessed during three preceding experiments. The low STB disease severity could not provide an additional tolerance evaluation, but the $\mathrm{T}$ could be connected to traits of healthy crops similarly to the study of Bancal et al. (2015).

\subsection{Tolerance and yield}

Foulkes et al. (2006) found that tolerance of STB might be negatively correlated with yield of healthy crops. They pointed out, however, it may indirectly result from a breeding strategy mainly focused on yield instead of tolerance. Tolerance indeed decreased with the year of release of the cultivar backgrounds of their studied NILs. The present experiment was based on doubled-haploid genotypes derived from crosses between modern cultivars and no correlation was found between tolerance and grain yield, either at the crop scale or shoot scale. This is in agreement with Bancal et al. (2015) who did not find a correlation between yield and tolerance and the recent work of Castro \& Simón (2016).

\subsection{TGW was co-limited by source and sink}

The six genotypes, contrasting for STB tolerance, showed a large range of TGW in the control S0. The spikelet removal treatment induced large variations in grain growth (TGW) reaching a maximum relative 
Table 3: Correlation between tolerance $(\mathrm{T})$ and grain tolerance $(\mathrm{Tg})$ and grain source or grain sink traits. The genotype tolerance grade $(T)$ was calculated as $-1 \times$ the genotype average of $x_{e g}$, beforehand standardized by environment (without unit). For each treatment combination $(\mathrm{S} \times \mathrm{F} \times \mathrm{N})$ the correlation was calculated on the 6 genotype values. The traits included the TGW $(\mathrm{g})$, the grain yield per ear $\left(\mathrm{Ye}, \mathrm{g} \cdot \mathrm{m}^{-2}\right)$ or per square metre $\left(\mathrm{Ym}, \mathrm{g} \cdot \mathrm{m}^{-2}\right)$, the grain number per ear $(\mathrm{GNe})$, HADg or HADe $\left(\mathrm{dm}^{2} \cdot{ }^{\circ} \mathrm{Cd} \cdot\right.$ grain $^{-1}$ or $\left.\mathrm{m}^{2} \cdot{ }^{\circ} \mathrm{Cd} \cdot \mathrm{m}^{-2}\right), \Delta$ indicates variable estimated after the time of the spikelet-removal treatment, 1 and 3 indicate the leaf layer when relevant, the last 3 lines are based on the difference between spikelet removal treatment and control.

\begin{tabular}{|c|c|c|c|c|c|c|c|c|}
\hline & $\mathrm{C} \times \mathrm{L} 14 \mathrm{~B}$ & $\mathrm{C} \times \mathrm{L} 5 \mathrm{H}$ & $\mathrm{C} \times \mathrm{L} 14 \mathrm{~B}$ & $\mathrm{LSP} 2 \times \mathrm{R} 127$ & $\mathrm{LSP} 2 \times \mathrm{R} 16$ & $\mathrm{LSP} 2 \times \mathrm{R} 20$ & Cor. $\mathrm{T}$ & Cor. Tg \\
\hline \multicolumn{9}{|l|}{ Tolerance } \\
\hline $\mathrm{T}$ & 0.23 & -0.02 & -1.45 & 0.81 & -0.48 & 0.91 & 1 & $0.98^{* * *}$ \\
\hline $\mathrm{Tg}$ & 0.977 & 0.975 & 0.961 & 0.987 & 0.975 & 0.987 & $0.98^{* * *}$ & 1 \\
\hline \multicolumn{9}{|c|}{ Complete ears (SO) } \\
\hline TGW & 46.8 & 42.7 & 38.7 & 47.4 & 42.9 & 45.1 & $0.90^{*}$ & $0.86^{*}$ \\
\hline $\mathrm{Ym}$ & 1070 & 911 & 824 & 868 & 1082 & 756 & -0.16 & -0.17 \\
\hline $\mathrm{Ye}$ & 2.5 & 2.3 & 2.3 & 2.4 & 2.8 & 2.3 & -0.04 & 0.06 \\
\hline GNe & 54 & 55 & 59 & 51 & 66 & 52 & -0.71 & -0.59 \\
\hline$\Delta \mathrm{TGW}$ & 39 & 32 & 31 & 30 & 34 & 35 & 0.24 & 0.15 \\
\hline$\Delta \mathrm{HADg}$ & 348 & 323 & 343 & 201 & 256 & 352 & -0.24 & -0.35 \\
\hline HADe 1 & 163 & 170 & 169 & 122 & 197 & 148 & -0.65 & -0.61 \\
\hline HADe 3 & 90 & 83 & 76 & 94 & 96 & 118 & 0.74 & 0.80 \\
\hline HADg 3 & 167 & 154 & 130 & 187 & 147 & 22.8 & $0.89^{*}$ & $0.89^{* * *}$ \\
\hline$\%$ LA 1 & 0.36 & 0.36 & 0.36 & 0.32 & 0.37 & 0.32 & -0.68 & -0.69 \\
\hline \%LA 3 & 0.29 & 0.29 & 0.28 & 0.32 & 0.27 & 0.33 & $0.88^{*}$ & $0.88^{*}$ \\
\hline \multicolumn{9}{|c|}{ Comparison (S1-SO) } \\
\hline$\Delta \mathrm{TGW}$ & 9.6 & 7.6 & 12.1 & 2.0 & 7.2 & 4.0 & $-0.85^{*}$ & $-0.92^{* *}$ \\
\hline$\Delta \mathrm{HADg}$ & 411 & 305 & 310 & 147 & 284 & 317 & -0.24 & -0.35 \\
\hline$\Delta$ HADg 3 & 76 & 42 & 36 & 36 & 30 & 87 & 0.55 & 0.45 \\
\hline
\end{tabular}

grain weight increase of $33 \%$ (39\% considering the grain weight increment since spikelet removal); this effect is large in comparison to similar studies of grain reduction impact on grain growth in wheat crops (Zhang et al. 2014, +12\%; Serrago et al. 2013, +32\%) or barley (Cartelle et al. 2006, $+15 \%$; Serrago et al. 2013, +7\%). With respect to the results of Borrás et al. (2004) and Slafer \& Savin (1994), a relationship between the relative grain weight increment since spikelet removal $(\Delta T G W, \%)$ and the relative grain source availability ( $d G N e$ or $\triangle H A D g, \%$ ) far below the 1:1 slope in our results denotes the genotypes were not only source limited. Nonetheless, as the relative TGW increase after the spikelet removal was significant and substantial, so the grain filling was not sink limited but rather co-limited by source and sink (Acreche \& Slafer, 2009). The genotype difference in TGW increase following spikelet removal could result from uncontrolled variations in treatment application, such as spikelet removal intensity or stage. However, as four among the six genotypes experienced similar sink reduction, their contrasting response to spikelet removal likely reflects their contrasting degree of source limitation (Zhang et al., 2014; Ma et al., 1996). Therefore, genotypes selected for their contrasting tolerance of STB also contrasted highly for TGW source limitation. 


\subsection{Low source limitation is a genotype tolerance trait}

In the control treatment S0 (intact ears) TGW was positively correlated with the STB-tolerance grade (T). Conversely, Bancal et al. (2015) suggested the tolerance of STB was negatively correlated with TGW. However, their results were based on a multiple field-experiment data and the correlation was driven by large variation in $\mathrm{N}$ fertilization level. When restricting the analysis to assays receiving a standard $\mathrm{N}$ fertilization, they no longer observed any TGW effect on tolerance.

The tolerant genotypes also showed the lowest response in grain weight increment following spikelet removal $\left(\Delta T G W_{S 1-S 0}\right)$. As a low response to spikelet removal suggests a low degree of source limitation in the control, then tolerance would be linked to low degree of source limitation during grain filling. Grain growth caused by the spikelet removal $\left(\Delta T G W_{S 1-S 0}\right)$ was negatively correlated with the control grain weight at maturity $\left(\mathrm{TGW}_{S 0}\right)$. This suggests that the genotypes exhibiting the heaviest control TGW were closer to their potential grain weight (Aisawi et al., 2015). The present results are consistent with those of Voltas et al. (1997) which also showed a larger increase in grain weight increment following sink reduction for smaller TGW genotypes ( $14.6 \%$ to $25.1 \%$ grain weight increase) for three barley genotypes; but the spikelet removal treatment was applied early at anthesis and might have altered the sink potential size (Dupont \& Altenbach, 2003; Calderini et al., 2001; Cartelle et al., 2006). Furthermore, Zhang et al. (2014) found that eight out of the nine wheat genotypes in a field experiment in China showed a similar negative relation between control grain weight and TGW increase following spikelet removal, although low TGW increases were observed $(<12 \%)$. Similarly, Serrago et al. (2011) using three contrasted cultivars found the TGW increase following fungicide treatment was highly correlated to healthy area absorption per grain $\left(\mathrm{HAA}_{\mathrm{G}}\right)$, a unique relationship being observed when $\mathrm{HAA}_{\mathrm{G}}$ was related to TGW of healthy crops. Overall, these results indicate that a low source limitation to grain, which depends on source-sink balance, is a genotype tolerant trait.

\subsection{The grain source?}

Although the present experiment did not produce a wide range of canopy green area, STB-tolerance T was found to be correlated with some of the traits describing the canopy, especially those related to the leaf 3. Thus, the leaf 3 proportion of the canopy area and the HADg3 positively correlated with T, while HADe3 and I3 were not far from being significant. Conversely no trait linked to flag leaf was found to be significant. The importance of leaf 3 was unexpected and may be explained by the low disease intensity, limiting most of the STB symptoms to the lower leaves which may have emphasized the link between tolerance and leaf 3 traits. According to Carretero et al. (2010), the leaf 3 relevance depends both on the extinction coefficient of leaf-layers and the vertical position of the disease in the canopy. We have not measured these parameters, but our study confirms that the leaf profile composition, the canopy leaf area and the senescence parameters could influence genotype tolerance by increasing the resource availability, despite more attention having been placed to date on the flag leaf (Foulkes et al., 2006; Bingham et al., 2009; Bancal et al., 2015). 
Other traits of tolerance were also previously proposed related to an increased radiation-use efficiency of remaining healthy area (Bingham et al., 2009; Ney et al., 2013) or the use of stored carbohydrates in the stem (Foulkes et al., 2006). Schierenbeck et al. (2016) stated that the biotroph P. triticina (leaf rust) reduced the RUE, while Py. tritici-repentis (tan spot) reduced the light interception. For a latent necrotoph pathogen such as Z. tritici (Sánchez-Vallet et al., 2015), the compensation could arise from an increased RUE of remaining green area (Ziv \& Eyal, 1978; Zuckerman et al., 1997) or an increased remobilisation of stored carbohydrate (Ney et al., 2013). Indeed some studies suggested the mobilisation of stem water soluble carbohydrates (WSC) somewhat compensated losses in HAD (Cornish et al., 1990; Gaunt \& Wright, 1992); but although Serrago et al. (2011) showed cultivars modified differently their WSC utilisation rates when diseased, they also concluded that in their experiments losses in $\mathrm{HAA}_{\mathrm{G}}$ were not compensated by observed increases in WSC mobilisation. As STB severity was low in the present study, it was therefore beyond the scope of this experiment to check for the physiological modifications of WSC remobilisation linked to the disease expression. Tolerance $(\mathrm{T})$ was not correlated with dry matter remobilisation from the stem or more generally from the above-ground biomass, but the present study was not designed to follow WSC dynamics over time and remobilisation was roughly estimated. Tolerance is generally thought to be associated either with higher grain source availability strategies or plant compensation mechanisms (such as the increase of the RUE, increased remobilisation, Ney et al., 2013). The present study gives more weight to the higher grain source availability by a predominant effect of low degree of source limitation.

\subsection{Tolerance estimation in healthy crops}

The degree of source-limitation at the grain level was the most consistent trait linked to the range of genotype tolerance observed in this experiment. The tolerance (T), that was estimated from Ym and HADm, can also be similarly calculated at the grain scale (Tg) using the TGW and HADg. The T index, established in the independent field STB-trials, was highly correlated with our healthy-trait based Tg; thus, it suggests STB tolerance was highly related to a higher degree of TGW source saturation. It is not surprising source-limited crops would be less tolerant to foliar damage by STB. Despite Tg being quite sensitive to imprecision in HADg estimation, our results show it could provide an alternative to usual tolerance assessments that are highly dependent on random epidemics. However, this relation at the grain scale has not been reported previously and needs to be explored on a larger range of genotypes and environmental conditions.

Similar to the study of Bancal et al. (2015), tolerance of STB assessed on our three independent trials was positively correlated with the traits observed in healthy crops of a fourth experiment. This is encouraging given the difficulty to ensure the STB epidemics in real crop conditions. Finally, if it is confirmed that the genotype crop tolerance of STB is correlated with tolerance at the grain scale (i.e. degree of TGW source limitation) then the spikelet removal treatment would be an adequate method to study tolerance of STB in 
to avoid possible uncertainty in trait correlations. The application of non-destructive proxy measurements of green area kinetics could also increase the availability and accuracy of HAD per grain estimations.

\section{Conclusion}

The source-sink traits observed in crops in the absence of STB damage to grain yield correlated with

the STB tolerance estimated in three independent site-season experiments. The degree of TGW source limitation at the grain scale ( $\mathrm{Tg})$ is highly and negatively correlated with the STB tolerance estimated at the crop scale $(\mathrm{T})$. The leaf area profile was shown to be linked to tolerance expression but the mechanism is still uncertain. Finally, the tolerance grade was not found to be correlated with the potential yield of the genotypes, suggesting breeding for tolerance traits is possible in high-yielding genotypes.

Borrás, L., Slafer, G. A., \& Otegui, M. E. (2004). Seed dry weight response to source sink manipulations in wheat, maize and soybean: a quantitative reappraisal. Field Crops Research, 86, 131-146. doi:10. 1016/j.fcr.2003.08.002. 
Bryson, R. J., Paveley, N. D., Clark, W. S., Sylvester-Bradley, R., \& Scott, R. K. (1997). Use of in-field measurements of green leaf area and incident radiation to estimate the effects of yellow rust epidemics on the yield of winter wheat. European Journal of Agronomy, 7, 53-62. doi:10.1016/S1161-0301(97) 00025-7.

Burke, J., \& Dunne, B. (2006). Septoria tritici in winter wheat - to spray or not to spray? Irish farmer, (pp. 14-18).

Calderini, D. F., Savin, R., Abeledo, L. G., Reynolds, M. P., \& Slafer, G. A. (2001). The importance of the period immediately preceding anthesis for grain weight determination in wheat. Euphytica, 119, 199-204. doi:10.1023/A:1017597923568.

Carretero, R., Serrago, R. A., Bancal, M. O., Perelló, A. E., \& Miralles, D. J. (2010). Absorbed radiation and radiation use efficiency as affected by foliar diseases in relation to their vertical position into the canopy in wheat. Field Crops Research, 116, 184-195. doi:10.1016/j.fcr.2009.12.009.

Cartelle, J., Pedró, A., Savin, R., \& Slafer, G. A. (2006). Grain weight responses to post-anthesis spikelettrimming in an old and a modern wheat under mediterranean conditions. European Journal of Agronomy, 25, 365-371. doi:10.1016/j.eja.2006.07.004.

Castro, A. C., \& Simón, M. R. (2016). Effect of tolerance to septoria tritici blotch on grain yield, yield components and grain quality in argentinean wheat cultivars. Crop Protection, 90, 66-76. doi:10.1016/ j.cropro.2016.08.015.

Cheval, P., Siah, A., Bomble, M., Popper, A. D., Reignault, P., \& Halama, P. (2017). Evolution of QoI resistance of the wheat pathogen Zymoseptoria tritici in Northern France. Crop protection, 92, 131-133. doi:10.1016/j.cropro.2016.10.017.

Conway, J., Eddelbuettel, D., Nishiyama, T., Prayaga, S. K., \& Tiffin, N. (2016). RPostgreSQL: R interface to the PostgreSQL database system. URL: https://CRAN.R-project.org/package=RPostgreSQL r package version 0.4-1.

Cornish, P. S., Baker, G. R., \& Murray, G. M. (1990). Physiological responses of wheat (triticum aestivum) to infection with Mycosphaerella graminicola causing Septoria tritici blotch. Australian Journal of Agricultural Research, 41, 317-327. doi:10.1071/AR9900317.

Crawley, M. J. (2012). The R book, 2nd edition. chapter Mixed-Effects Models. (pp. 681-714). Wiley. ISBN 978-0-470-97392-9.

Dupont, F. M., \& Altenbach, S. B. (2003). Molecular and biochemical impacts of environmental factors on wheat grain development and protein synthesis. Journal of Cereal Science, 38, 133-146. doi:10.1016/ S0733-5210(03) 00030-4. 
Egli, D. B., \& Bruening, W. P. (2001). Source-sink relationships, seed sucrose levels and seed growth rates in soybean. Annals of botany, 88, 235-242. doi:10.1006/anbo.2001.1449.

Foulkes, M. J., Paveley, N. D., Worland, A., Welham, S. J., Thomas, J., \& Snape, J. W. (2006). Major genetic changes in wheat with potential to affect disease tolerance. Phytopathology, 96, 680-688. URL: http://apsjournals .apsnet.org/doi/pdf/10.1094/PHYTO-96-0680.

Fraaije, B. A., Lucas, J. A., Clark, W. S., \& Burnett, F. J. (2003). Qol resistance development in populations of cereal pathogens in the UK. In Proceedings of the BCPC International Congress, Crop Science and Technology 689-694. Alton, Hampshire, UK: The British Crop Protection Council.

Gaunt, R. E., \& Wright, A. C. (1992). Disease-yield relationship in barley. II. Contribution of stored stem reserves to grain filling. Plant Pathology, 41,688-701. doi:10.1111/j.1365-3059.1992.tb02552.x.

Lenth, R. V. (2016). Least-squares means: The R package lsmeans. Journal of Statistical Software, 69, 1-33. doi:10.18637/jss.v069.i01.

Ma, Y.-Z., MacKown, C. T., \& van Sanford, D. A. (1996). Differential effects of partial spikelet removal and defoliation on kernel growth and assimilate partitioning among wheat cultivars. Field Crops Research, 47, 201-209. doi:10.1016/0378-4290(96)00016-0.

Ney, B., Bancal, M. O., Bancal, P., Bingham, I. J., Foulkes, J., Gouache, D., Paveley, N., \& Smith, J. (2013). Crop architecture and crop tolerance to fungal diseases and insect herbivory. Mechanisms to limit crop losses. European Journal of Plant Pathology, 135, 561-580. doi:10.1007/s10658-012-0125-z.

Parker, S., Welham, S., Paveley, N., Foulkes, J., \& Scott, R. K. (2004). Tolerance of Septoria leaf blotch in winter wheat. Plant Pathology, 53, 1-10. doi:10.1111/j.1365-3059.2004.00951.x.

Pinheiro, J., Bates, D., DebRoy, S., Sarkar, D., \& R Core Team (2017). nlme: Linear and Nonlinear Mixed Effects Models. URL: https://CRAN.R-project.org/package=nlme r package version 3.1-131.

R Core Team (2017). R: A Language and Environment for Statistical Computing. R Foundation for Statistical Computing Vienna, Austria. URL: https://www.R-project.org/.

R Special Interest Group on Databases (2014). DBI: $R$ Database Interface. URL: https://CRAN. $\mathrm{R}$-project .org/package=DBI r package version 0.3.1.

Reynolds, M., Pask, A., \& Mullan, D. (2012). Physiological breeding I: interdisciplinary approaches to improve crop adaptation. Mexico, Mexico, DF (Mexico): CIMMYT. URL: http://repository . cimmyt. org/xmlui/bitstream/handle/10883/1288/96144.pdf.

Reynolds, M. P., Pellegrineschi, A., \& Skovmand, B. (2005). Sink-limitation to yield and biomass: a summary of some investigations in spring wheat. Annals of applied biology, 146, 39-49. doi:10.1111/j. $1744-7348.2005 .03100 . x$. 
Salmon, S. C., \& Laude, H. H. (1932). Twenty years of testing varieties and strain of winter wheat at the Kansas agricultural experiment station. Technical bulletin 80 Kansas state college of agriculture and applied science Manhattan, Kansas. URL: https://www.k-state.edu/historicpublications/pubs/ STB030.PDF.

Sánchez-Vallet, A., McDonald, M. C., Solomon, P. S., \& McDonald, B. A. (2015). Is Zymoseptoria tritici a hemibiotroph? Fungal Genetics and Biology, 79, 29 - 32. doi:10.1016/j.fgb.2015.04.001. Septoria tritici blotch disease of wheat: Tools and techniques to study the pathogen Zymoseptoria tritici.

Sarkar, D. (2008). Lattice: Multivariate Data Visualization with $R$. New York: Springer. URL: http: //lmdvr.r-forge.r-project.org ISBN 978-0-387-75968-5.

Schafer, J. (1971). Tolerance to plant disease. Annual review of phytopathology, 9, 235-252. doi:10.1146/ annurev py. 09.090171.001315.

Schierenbeck, M., Fleitas, M. C., Miralles, D. J., \& Simón, M. R. (2016). Does radiation interception or radiation use efficiency limit the growth of wheat inoculated with tan spot or leaf rust? Field Crops Research, 199, 65-76. doi:10.1016/j.fcr.2016.09.017.

Serrago, R. A., Alzueta, I., Savin, R., \& Slafer, G. A. (2013). Understanding grain yield responses to source-sink ratios during grain filling in wheat and barley under contrasting environments. Field Crops Research, 150, 42-51. doi:10.1016/j.fcr.2013.05.016.

Serrago, R. A., Carretero, R., Bancal, M.-O., \& Miralles, D. J. (2011). Grain weight response to foliar diseases control in wheat (triticum aestivum 1.). Field Crops Research, 120, 352-359. doi:10.1016/j. fcr.2010.11.004.

Shearman, V. J., Sylvester-Bradley, R., Scott, R. K., \& Foulkes, M. J. (2005). Physiological processes associated with wheat yield progress in the uk. Crop Science, 45, 175-185.

Slafer, G. A., \& Savin, R. (1994). Source-sink relationships and grain mass at different positions within the spike in wheat. Field Crops Research, 37, 39-49. doi:10.1016/0378-4290(94)90080-9.

Smith, R. J. (2009). Use and misuse of the reduced major axis for line-fitting. American Journal of Physical Anthropology, 140, 476-486. doi:10.1002/ajpa.21090.

Voltas, J., Romagosa, I., \& Araus, J. L. (1997). Grain size and nitrogen accumulation in sink-reduced barley under mediterranean conditions. Field Crops Research, 52, 117-126. doi:10.1016/S0378-4290(96) 01067-2.

Zadoks, J. C., Chang, T. T., \& Konzak, C. F. (1974). A decimal code for the growth stages of cereals. Weed Research, 44, 415-421. doi:10.1111/j.1365-3180.1974.tb01084.x. 
Zhang, Y.-H., Sun, N.-N., Hong, J.-P., Zhang, Q., Wang, C., Qing-Wu, X., Shun-Li, Z., Qin, H., \& Zhi-

Min, W. (2014). Effect of source-sink manipulation on photosynthetic characteristics of flag leaf and the remobilization of dry mass and nitrogen in vegetative organs of wheat. Journal of integrative agriculture, 13, 1680-1690. doi:10.1016/S2095-3119(13)60665-6.

Ziv, O., \& Eyal, Z. (1978). Assessment of yield component losses caused in plants of spring wheat cultivars by selected isolates of Septoria tritici. Phytopathology, 68, 791-796. URL: http://apsnet.org/ publications/phytopathology/backissues/Documents/1978Articles/Phyto68n05_791.pdf.

Zuckerman, E., Eshel, A., \& Eyal, Z. (1997). Physiological aspects related to tolerance of spring wheat cultivars to septoria tritici blotch. Phytopathology, 87, 60-65. URL: http://apsjournals.apsnet.org/ doi/pdf/10.1094/PHYTO.1997.87.1.60. 